University of Nebraska - Lincoln

DigitalCommons@University of Nebraska - Lincoln

Faculty Publications: Department of Entomology

2000

Strepsipteran Parasitism of White Leafhoppers, Cofana spp. (Hemiptera: Cicadellidae) in Lowland Rice in Côte d'Ivoire

I. O. Oyediran

A. Ndongidila

E. A. Heinrichs

Follow this and additional works at: https://digitalcommons.unl.edu/entomologyfacpub

Part of the Agriculture Commons, Agronomy and Crop Sciences Commons, and the Entomology Commons

This Article is brought to you for free and open access by the Entomology, Department of at DigitalCommons@University of Nebraska - Lincoln. It has been accepted for inclusion in Faculty Publications: Department of Entomology by an authorized administrator of DigitalCommons@University of Nebraska - Lincoln. 


\title{
Strepsipteran Parasitism of White Leafhoppers, Cofana spp. (Hemiptera: Cicadellidae) in Lowland Rice in Côte d'Ivoire
}

\author{
I. O. Oyediran, ${ }^{1}$ A. Ndongidila, ${ }^{2}$ and E. A. Heinrichs ${ }^{1}$ \\ 1. Department of Entomology, University of Nebraska, Lincoln, Nebraska, USA \\ 2. West Africa Rice Development Association (WARDA), 01 B.P. 2551 Bouaké, Côte d'Ivoire
}

Corresponding author - E. A. Heinrichs, Department of Entomology, University of Nebraska, 202 Plant IndustryEast Campus, Lincoln, NE 68583-0816, USA, fax +1 (402) 472-4687, email eheinrichs2@unl.edu

\begin{abstract}
Three tests were conducted over a 2-year period in lowland irrigated rice fields on the WARDA Research Station at Bouaké, Côte d'Ivoire, to obtain information on the strepsipteran parasitism of white leafhoppers, Cofana spectra and C. unimaculata. Rice cultivars were sampled with a sweep net to collect leafhoppers for determination of the relative abundance of the two leafhopper species and the effect of rice cultivar and rice crop age on the leafhopper populations and percent strepsipteran parasitism. Dissections of the leafhoppers were made to determine the relative number of the various parasitic stages in the leafhoppers. Cofana unimaculata populations were higher than those of $C$. spectra while C. spectra parasitism by Halictophagus australensis Perkins (Strepsiptera: Halictophagidae) was higher than that of $C$. unimaculata. In two tests, there was a relationship between length of rice cultivar duration and C. unimaculata populations with populations being highest on the short duration cultivars. On most cultivars there was no correlation between Cofana populations and percentage parasitism, nor was there a relationship between cultivar growth duration and percent parasitism. The number of the various stages of the parasite was similar in both Cofana species with the male pupal parasitic stage being most common.
\end{abstract}

Keywords: Côte d'Ivoire, Oryza sativa L., rice insect pests, white leafhoppers, Cofana spectra (Distant), Cofana unimaculata (Signoret), Strepsiptera, Halictophagus australensis, parasitism, West Africa 


\section{Introduction}

The white leafhoppers, Cofana spectra (Distant) and C. unimaculata (Signoret) are believed to occur throughout West Africa (Descamps, 1956) and have a wide distribution in the Old World Tropics from Africa to Australia (Wilson and Claridge, 1991). The two species are the largest of the leafhoppers occurring in rice in West Africa. They are currently considered minor pests of rice in Côte d'Ivoire but are considered major pests in Nigeria (Emosairue and Usua, 1996). Cofana spectra is also considered an important pest of rice in India (Sam and Chelliah, 1984). Both adults and nymphs are xylem feeders and suck sap from leaves (Wilson and Claridge, 1985). Leaf tips dry and later the leaves turn orange in color and curl. Feeding by large numbers of Cofana spp. can cause stunting of rice plants, and severe infestations can cause plant death (Sam and Chelliah, 1984).

Both Cofana species occur in all rice environments, but they are most common in lowland rice fields. They are present throughout the year in continuously cropped lowland rice on the WARDA Research Station at Bouaké, Côte d'Ivoire (Heinrichs and Barrion, 2000). Low populations occur from December to March and then increase with the beginning of the rainy season in April and reach a peak at the end of the rainy season in November. Within a crop, populations occur from transplanting until harvest, but peak populations occur at 6 weeks after transplanting (late tillering phase of crop growth), and by 12 weeks (flowering phase of crop growth) populations are very low.

Hirashima and Kifune (1978) reported Halictophagus spectrus Yang (Strepsiptera: Halictophagidae) parasitizing Cicadella spectra (= Cofana spectra) for the first time in rice in Sarawak, Malaysia, in 1976. Reissig et al. (1986) and Barrion and Litsinger (1983) listed several natural enemies attacking Cofana spectra in Asia. In studies conducted in the Philippines, they reported that about $50 \%$ of the C. spectra nymphs and adults collected in the field were parasitized by H. spectrus. Later, Barrion and Litsinger (1987) reported on a survey conducted in the Philippines where strepsipteran parasitism by Halictophagus bipunctatus on leafhoppers Nephotettix virescens (Distant) and N. nigropictus (Stål) and by Elenchus sp. on the planthoppers Sogatella spp. and Tagosodes pusanus (Distant) ranged from 0.1 to $11.0 \%$.

There is little information on strepsipteran parasitism of rice leafhoppers in Africa. Reporting on Strepsiptera in the British Museum (Natural History), London, Fox (1967) named Halictophagus regina as a new species taken from Cofana spectra on "swamp grass" in Uganda in 1963. Olmi (1998) reared Halictophagus australensis Perkins from Cofana spectra collected in Maputo, Mozambique. In routine surveys conducted in farmers' rice fields in Côte d'Ivoire the white leafhoppers Cofana spp. had a high rate of strepsipteran parasitism (Heinrichs, 1995). He reported that Halictophagus sp. was a common parasite of C. spectra and C. unimaculata on the WARDA Research Station and in farmers' fields throughout Côte d'Ivoire. Parasitism over seven sites in Côte d'Ivoire averaged 21\% for C. spectra and $10 \%$ for C. unimaculata. Parasitism of both species was higher in the northern part of the country, in the savanna zone, as compared with the forest zone in the south.

The biology of Strepsiptera is unusual and has been described by Shepard et al. (1986) and Kathirithamby (1989). The males are free-living and winged, whereas females are wingless and legless and do not leave the host. The male, upon emerging from the host, seeks out the female and mates with it. The female may viviparously produce up to 2000 
minute larvae, which escape from its body and from the body of the host, and on to the rice plant. These larvae, called triungulins, have well-developed eyes and legs with which they locate new hosts. The larvae attach themselves to the host, Cofana spp., when they move on the rice plant, and penetrate them. Once inside the body of the host, the parasite molts into a legless, wormlike stage that feeds in the body of the host. After molting several times, it pupates. Male adults then leave the host while females remain in the host with the anterior portion of the body protruding between the abdominal segments of the host. After the young are produced, the female dies. The host may not be killed, but sex organs are damaged by the physical presence of the parasite, resulting in sterilization.

To meet the demand for increased rice production in West Africa, national and international rice breeding programs are developing high-yielding lowland rice cultivars for cultivation in the inland swamp ecosystem. The white leafhoppers, Cofana spp., are abundant in this ecosystem. Owing to the apparent importance of strepsipteran parasitism in suppressing populations of Cofana spp. in West Africa, a study was conducted to assess the degree of parasitism as affected by rice cultivar and rice plant age, and to determine the relationship between Cofana spp. populations and percent Cofana spp. parasitism. To obtain preliminary biological information on the parasite/Cofana relationship, the relative abundance of the various parasitic stages present in the leafhopper hosts was determined.

\section{Methods}

Three tests were conducted in lowland rice fields on the WARDA research station, $30 \mathrm{~km}$ east of Bouaké, Côte d'Ivoire. The first two tests were conducted during the rainy season of 1993 and the third during the rainy season of 1994. Methods were similar in the three tests except for the rice cultivars, which varied. The rice cultivars were planted as production plots with dimensions of $25 \times 98 \mathrm{~m}$. Rice cultivars selected for the study included those currently being grown by farmers in the region and elite breeding lines that are being evaluated for possible release for commercial cultivation. These cultivars vary in their growth duration (time in days from seeding of the nursery to harvest). Short and long duration cultivars were included in each test. In the first test, cultivars Bouaké 189 (100 days growth duration) and ITA 324 (145 days) were planted on July 21. In the second test V 55 (90 days) and IDSA 10 (110 days) were planted on October 22. In the third test, rice cultivars WAB 638-2 (135 days), ITA 328 (140 days), ITA 402 (136 days), and BG 90-2 (100 days) were planted on March 28, 1994. Of the cultivars tested, Bouaké 189 and BG 90-2 are the most widely grown lowland cultivars in West Africa.

Cofana spectra and C. unimaculata adults were collected with a sweep net at irregular intervals (usually 2-5 days) until the Cofana spp. population reached zero, or near zero. One thousand sweeps were taken per rice cultivar on each sampling date. The Cofana spp. were preserved in alcohol and returned to the laboratory for sorting into species and counting. The Cofana spp. were dissected to determine whether they were parasitized with Halictophagus sp. Parasite stages were identified, counted, and classified as: (1) larvae, (2) male pupae, (3) female adult with larvae (larvid), (4) female adult with eggs (gravid), and (5) female adult without larvae or eggs (empty). 
Data on C. unimaculata and C. spectra populations and percent parasitism were analyzed using analysis of variance procedures. Standard error of the means were determined and means compared at the $P=0.05$ level. Pearson correlation coefficients were conducted using the SAS system to determine the correlation of parasitism rates between C. unimaculata and C. spectra on the rice cultivars over the crop growth period and to determine the correlation between the numbers of each Cofana sp. collected and the percentage parasitism on the rice cultivars.

Specimens of the Halictophagus from Cofana sp. collected at the research site were sent to Dr. J. Kathirithamby, Department of Zoology, Oxford University, and identified as Halictophagus australensis Perkins. According to Dr. Kathirithamby (personal communication), H. australensis occurs throughout southeast Asia, Japan, and Australia, and the record from Mozambique as reported in Olmi's paper (1998) was based on her identification. Perkins described this species in 1905 and described the host as Tettigonia (Orthoptera: Tettigoniidae). The host has now been established as Cofana spectra (Distant). An early distribution record is that in Pierce's (1909) revision of Strepsiptera in which he reported H. australensis from Queensland, Australia, hence the specific name. Halictophagus spectrus Yang 1964, commonly reported as a parasite of Cofana spectra in Asia, and H. helleri Kinzelbach 1971, are both synonyms of $H$. australensis (Kathirithamby, 1992).

\section{Results}

The rice cultivar effect on Cofana spp. populations is shown in Figure 1. On all rice cultivars, Cofana unimaculata populations were higher than those of $C$. spectra, with a mean ratio of 6:1. There was no difference between the two Cofana species on either Bouaké 189 or ITA $324(P>0.05 ; \mathrm{df}=11)($ figure $1(\mathrm{~A}))$, but there was a difference between the two species on all other cultivars (figure $1(\mathrm{~B}), P<0.05 ; \mathrm{df}=13$ : figure $1(\mathrm{C}), P<0.05 ; \mathrm{df}=5$ ).

In the first test, the Cofana unimaculata population was highest on cultivar Bouaké 189 and lowest on ITA $324(P<0.05 ; \mathrm{df}=11)$ (figure $1(\mathrm{~A})$ ). In the second test, $C$. unimaculata populations were highest on V 55 and lowest on IDSA $10(P<0.05 ; \mathrm{df}=13)$ (figure $1(\mathrm{~B}))$. Populations in the third test were highest on ITA 402 and lowest on WAB 638-2 $(P<0.05$; $\mathrm{df}=5)($ figure $1(C))$. 


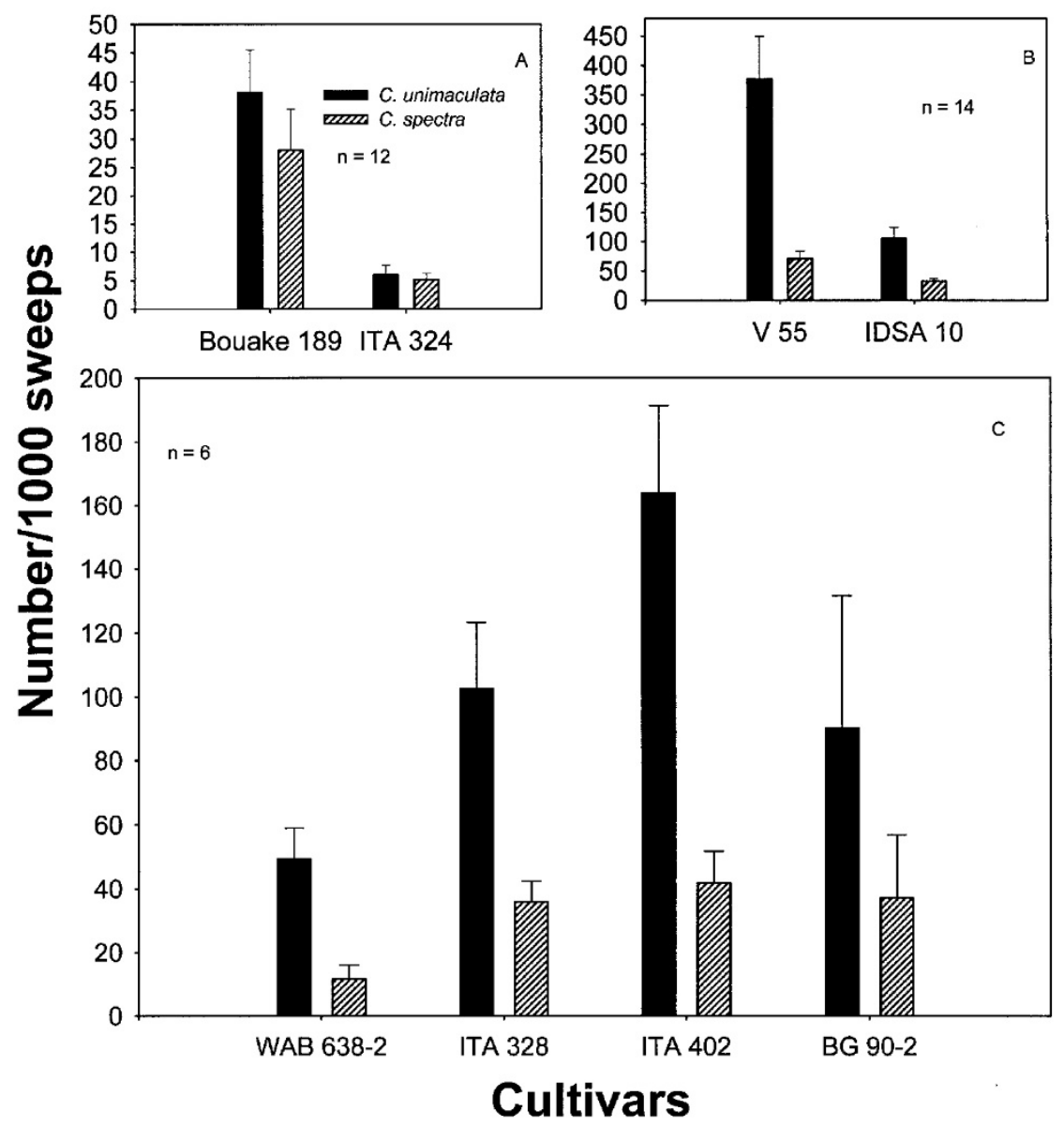

Figure 1. Rice cultivar effect on Cofana unimaculata and C. spectra adult populations (mean \pm SE) under lowland irrigated rice field conditions. (A) Test 1, Bouaké 189 (100-day duration) and ITA 324 (145-day duration), transplanted 23 July 1993. (B) Test 2, V 55 (90-day duration) and IDSA 10 (110-day duration), transplanted October 20, 1993. (C) Test 3, WAB 638-2 (135-day duration), ITA 328 (140-day duration), ITA 402 (136-day duration), and BG 90-2 (100-day duration), transplanted 28 March 1994. WARDA Research Station, Bouaké, Côte d'Ivoire.

Halictophagus parasitism of the two Cofana species on different rice cultivars, in relation to number of days after transplanting, is indicated in figures 2 and 3 . In the first and second tests, over all sampling dates, parasitism of $C$. spectra was higher $(P<0.05)$ than that of $C$. unimaculata on all rice cultivars (figure 2). Mean parasitism for C. unimaculata and C. spectra over all sampling dates was $14 \%$ and $28 \%$, respectively. Percentage parasitism of both Cofana species increased with crop age reaching a peak at about 70-88 days after transplanting, with a sharp decrease thereafter (figure 2). 


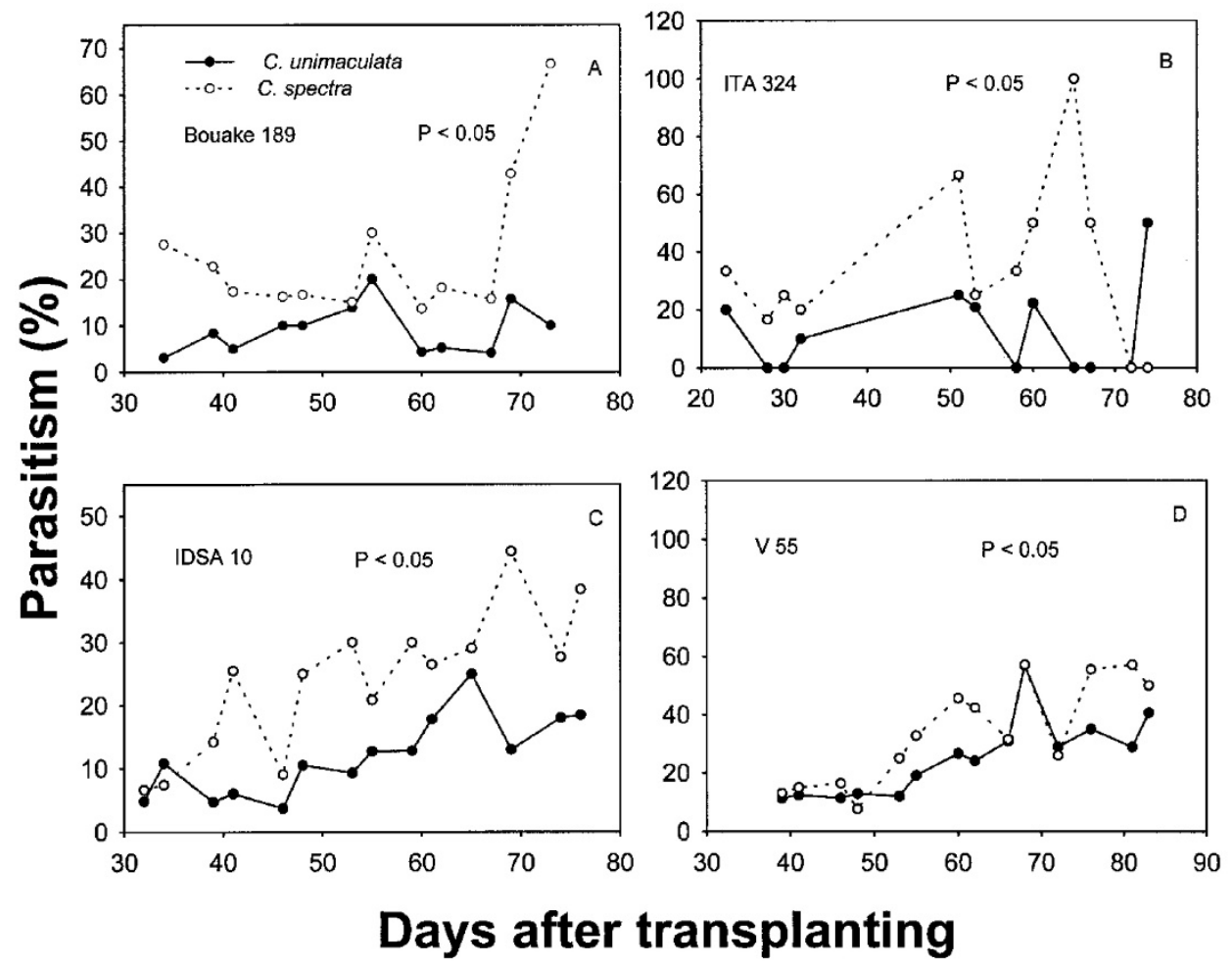

Figure 2. Cofana unimaculata and C. spectra parasitism by Halictophagus australensis (\%) at indicated days after transplanting of rice cultivars in lowland irrigated fields. $P<0.05$ indicates a significant difference in percent parasitism between the two Cofana species at the 5\% level by an analysis of variance (A) Test 1, Bouaké 189 (100-day duration) transplanted 23 July 1993. (B) Test 1, ITA 324 (145-day duration), transplanted 23 July 1993. (C) Test 2, IDSA 10 (110-day duration), transplanted October 20, 1993. (D) Test 2, V 55 (90day duration), transplanted October 20, 1993. WARDA Research Station, Bouaké, Côte d'Ivoire.

In the third test, parasitism of $C$. unimaculata was higher $(P<0.05 ; \mathrm{df}=5)$ than that $C$. spectra on WAB 638-2 (figure 3(A)) while parasitism of $C$. spectra was higher $(P<0.05 ; \mathrm{df}=$ 5 ) than that of $C$. unimaculata on ITA 328 (figure 3(B)). There was no difference in parasitism between Cofana species on ITA 402 or BG 90-2 $(P>0.05$; df $=5$ ) (figure $3(C$ and D)). Mean parasitism for C. unimaculata and C. spectra over all sampling dates in the third test was $18 \%$ and $25 \%$, respectively. The percent parasitism of the two Cofana species in relation to rice crop age was fairly constant throughout the 6-week sampling period. Parasitism was high within 1 week after transplanting, indicating that strepsipteran infestation of the white leafhoppers probably occurred prior to leafhopper invasion of the rice cultivars. Parasitism of $C$. unimaculata over the sampling period ranged from a low of $8 \%$ on ITA 328 (figure 3 (B)) to a high of $45 \%$ on BG $90-2$ (figure 3 (D)) over the 6-week sampling period. Parasitism of C. spectra over this same period ranged from a low of $10 \%$ on WAB $638-2$ (figure 3(A)) to a high of 70\% on BG 90-2 (figure 3(D)). 

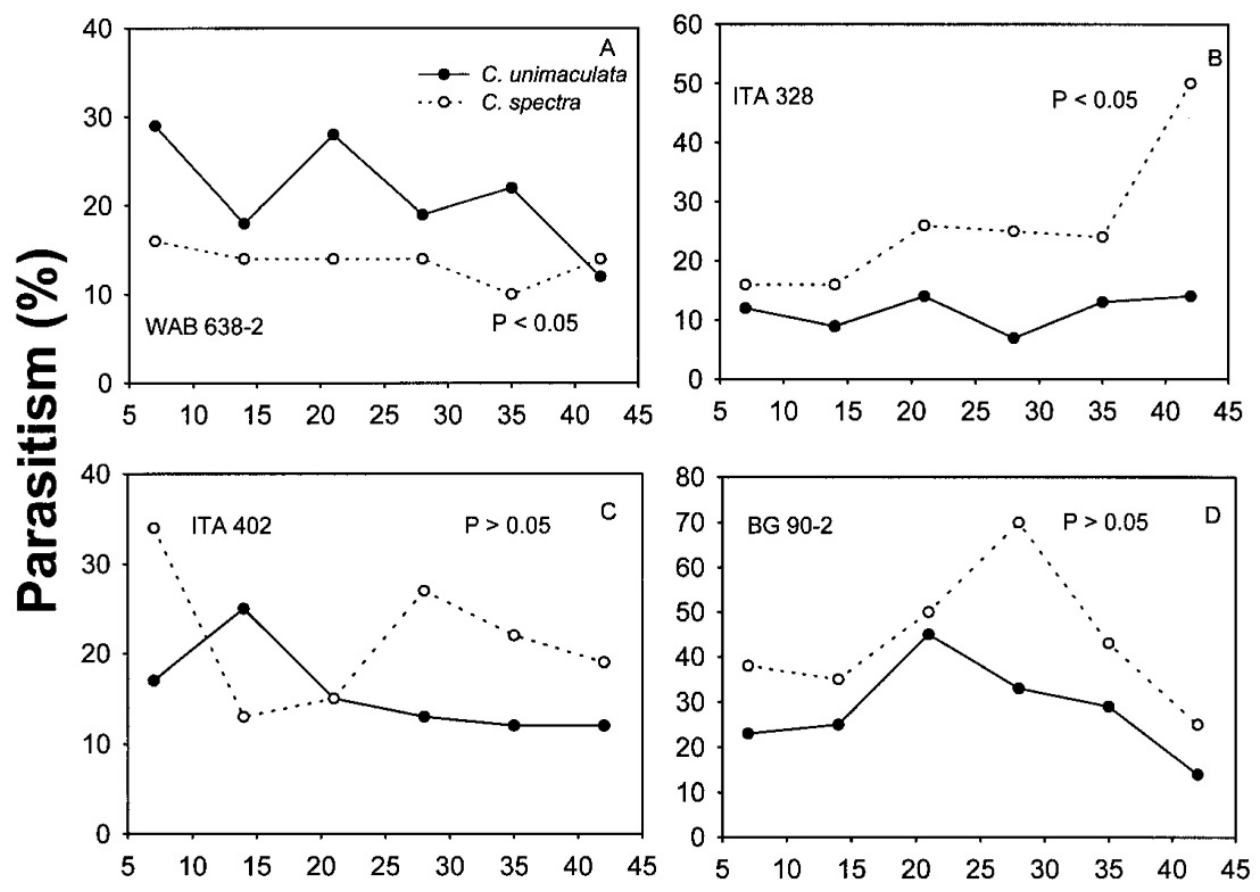

Days after transplanting

Figure 3. Percent Cofana unimaculata and C. spectra parasitism by Halictophagus australensis at indicated days after transplanting (test 3 transplanted 28 March 1994) of rice cultivars in lowland irrigated fields. $P<0.05$ indicates a significant difference in percent parasitism between the two Cofana species at the $5 \%$ level by an analysis of variance (A) WAB 638-2 (135-day duration), (B) ITA 328 (140-day duration), (C) ITA 402 (136-day duration), and (D) BG 90-2 (100-day duration). WARDA Research Station, Bouaké, Côte d'Ivoire.

Mean percent strepsipteran parasitism of the two Cofana species on the rice cultivars over the entire sampling period in the three tests is shown in figure 4 . Parasitism in the first test was similar $(P>0.05 ; \mathrm{df}=11)$ on the two cultivars (figure $4(\mathrm{~A}))$. In the second test (figure 4(B)), parasitism of $C$. unimaculata was higher on rice cultivar V 55 than on IDSA 10 $(P<0.05 ; \mathrm{df}=13)$. There was no difference between rice cultivars in $C$. spectra parasitism $(P$ $>0.05 ; \mathrm{df}=13$ ). In the third test (figure $4(\mathrm{C})$ ), C. unimaculata parasitism was highest on BG 90-2 $(P<0.05 ; \mathrm{df}=5)$. Cofana spectra parasitism on BG 90-2 was higher than that on ITA 328 or ITA $402(P<0.05 ; \mathrm{df}=5)$. 


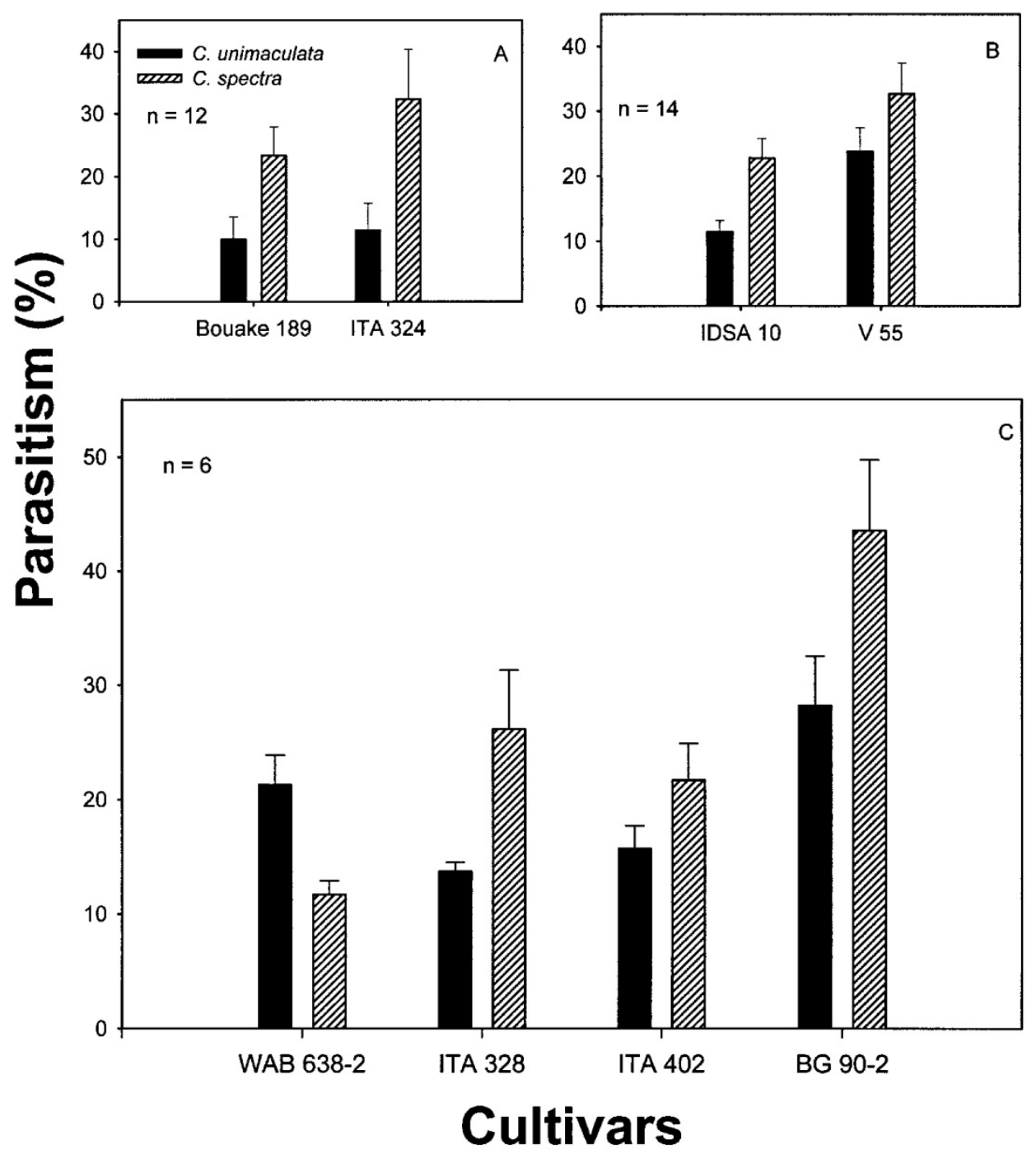

Figure 4. Mean \pm SE Cofana unimaculata and C. spectra parasitism by Halictophagus australensis on rice cultivars in lowland irrigated fields. Statistical comparisons are made between rice cultivars for each Cofana species. (A) Test 1, Bouaké 189 (100-day duration), ITA 324 (145-day duration). (B) Test 2, IDSA 10 (110-day duration), and V 55 (90-day duration). (C) Test 2, WAB 638-2 (135-day duration), ITA 328 (140-day duration), ITA 402 (136-day duration), and BG 90-2 (100-day duration). WARDA Research Station, Bouaké, Côte d'Ivoire.

The relationship between Cofana spp. population levels and percentage of Cofana spp. parasitism by Halictophagus on the various rice cultivars is given in Table 1. The correlations were generally low, indicating that Cofana population levels were not related to percentage parasitism. There were a few exceptions, however. The correlation $(r)$ for C. spectra on WAB 638-2 was 0.71 (positive) and C. spectra on ITA 402 was 0.95 (positive). Cofana 
unimaculata on ITA 402 was a negative 0.63 indicating a decrease in the C. unimaculata population with an increase in parasitism.

Table 1. Relationship between number of Cofana spp. and percentage strepsipteran, Halictophagus australensis parasitism of Cofana spp. on different rice cultivars. WARDA Research Station, Bouaké, Côte d'Ivoire

\begin{tabular}{llccc}
\hline Cultivar & \multicolumn{1}{c}{ Cofana species } & $\begin{array}{c}\text { Coefficient of } \\
\text { Correlation }(r)\end{array}$ & $\begin{array}{c}\text { Coefficient of } \\
\text { determination }\left(r^{2}\right)\end{array}$ & $\begin{array}{c}\text { Regression } \\
\text { equation }\end{array}$ \\
\hline Bouaké 189 & C. unimaculata & 0.39 & 0.150 & $y=13.2-0.08 x$ \\
C. spectra & 0.14 & 0.020 & $y=26.0-0.09 x$ \\
ITA 324 & C. unimaculata & 0.24 & 0.060 & $y=7.5+0.60 x$ \\
V55 5 C. spectra & 0.05 & 0.002 & $y=33.9-0.30 x$ \\
IDSA 10 & C. unimaculata & 0.56 & 0.320 & $y=34.6-0.03 x$ \\
& C. spectra & 0.48 & 0.230 & $y=45.7-0.18 x$ \\
WAB-638-2 & C. unimaculata & 0.10 & 0.009 & $y=12.4-0.01 x$ \\
ITA 328 & C. spectra & 0.17 & 0.030 & $y=19.3+0.11 x$ \\
& C. unimaculata & 0.09 & 0.008 & $y=20.6+0.01 x$ \\
ITA 402 & C. spectra & 0.71 & 0.500 & $y=3.4+0.48 x$ \\
& C. unimaculata & 0.05 & 0.002 & $y=11.2+0.01 x$ \\
BG 90-2 & C. spectra & 0.02 & 0.040 & $y=31.8-0.16 x$ \\
& C. unimaculata & 0.63 & 0.390 & $y=23.2-0.05 x$ \\
All cultivars combined & C. spectra & 0.95 & 0.900 & $y=8.4+0.30 x$ \\
& C. unimaculata & 0.26 & 0.070 & $y=30.6-0.03 x$ \\
& C. spectra & 0.30 & 0.090 & $y=47.0-0.09 x$ \\
& C. spectra & 0.10 & 0.009 & $y=14.7+0.01 x$ \\
& & 0.03 & 0.001 & $y=27.6-0.02 x$ \\
\hline
\end{tabular}

Dissections of adult Cofana sp. to determine the relative abundance of the various $H$. australensis stages present indicated the presence of five stages; larvae, male pupae, females with larvae in their abdomen (larvid), females with eggs in their abdomen (gravid), and females without eggs or larvae (empty) (figure 5). In the first test, C. unimaculata and C. spectra were separated by species and sex prior to dissection. There was no difference in percentage parasitism between males and females of the two Cofana species, and the sexes were combined in calculating the results of the three tests. Results for the two Cofana species were similar (figure 5(A and B)), and the two Cofana species were combined in the third test (figure 5(C)). The most common number of adult Halictophagus in a given leafhopper was one but as many as six were observed. Male pupae were the most common stage observed for both C. unimaculata and C. spectra. Larvae, larvid females, and gravid females were about equal in number, being about one-third that of male pupae. Female Halictophagus with neither eggs nor larvae (F empty) were the least abundant. On a percentage basis, $11 \%$ of the parasites were larvae, $57 \%$ male pupae, $11 \%$ larvid females, $19 \%$ gravid females, and $2 \%$ empty females. 


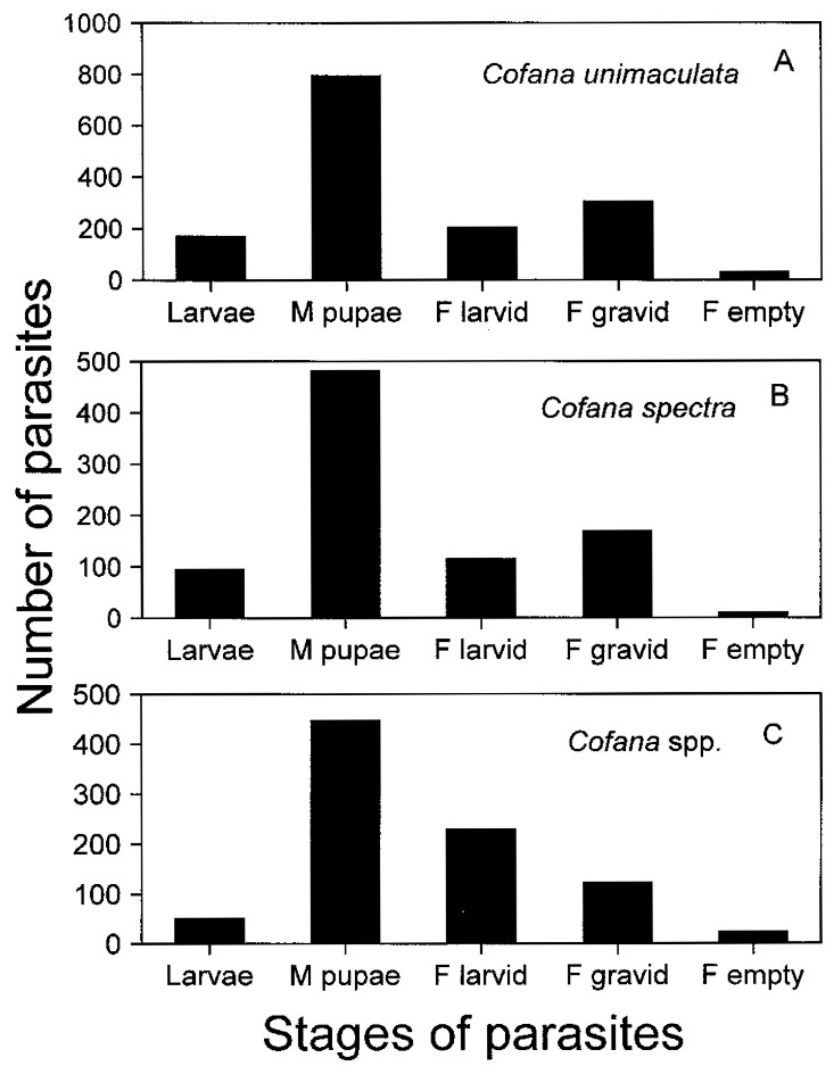

Figure 5. Number of each of the growth stages of Halictophagus australensis in Cofana adults collected from rice cultivars in lowland irrigated fields. Larvae = parasitic larval stage; $\mathrm{M}$ pupae = male pupae; F larvid $=$ female with larvae; F gravid $=$ female with eggs; $F$ empty $=$ female with neither eggs nor larvae. (A) Data based on dissections of C. unimaculata (360 males and 670 females) collected from rice cultivars Bouaké 189, ITA 324, IDSA 10 and V 55 in the 1993 study. (B) Data based on dissections of C. spectra (232 males and 369 males) collected from rice cultivars Bouaké 189, ITA 324, IDSA 10 and V 55 in the 1993 study. (C) Data based on dissections of 628 Cofana unimaculata and C. spectra (species combined) collected from rice cultivars WAB 638-2, ITA 328, ITA 402, and BG 90-2 in the 1994 study. WARDA Research Station, Bouaké, Côte d'Ivoire.

\section{Discussion and conclusions}

Percentage H. australensis parasitism of Cofana observed in this study was generally similar to that reported in other regions of the world. In Sarawak, Malaysia, for example, C. spectra parasitism of about $10 \%$ for pipunculids, dryinids, and Strepsiptera was reported (Sarawak Department of Agriculture, 1985), while reports from the Philippines showed strepsipteran parasitism ranging from $50 \%$ in one study (Barrion and Litsinger, 1983) to $11 \%$ in another study (Barrion and Litsinger, 1987). Various biological and environmental factors, such as the host leafhopper population, weather conditions, rice cultivar, and age of rice 
and time of the year (wet season vs. dry season) when sampling is conducted, may have determined the rates of parasitism in the different studies.

There was a general relationship between the growth duration of the rice cultivars and Cofana unimaculata populations in tests 1 and 2. In test 1, Bouaké 189, a short duration cultivar (100 days), had a high population whereas ITA 324, a long duration cultivar (145 days), had a low population (figure 1(A)). In test 2, V 55 a short duration cultivar (90 days), had a higher $C$. unimaculata population than IDSA 10, with an intermediate growth duration (110 days). These results indicate the importance of monitoring insect pests on rice cultivars when they are being evaluated at experiment stations prior to release to farmers. There was no apparent relationship between crop growth duration and percent parasitism. Further studies with a greater range of crop growth durations are necessary to verify the relationship between rice growth duration and Cofana spp. populations and subsequent strepsipteran parasitism levels.

In tests 1 and 2, percentage parasitism of Cofana spectra increased with crop age on all rice cultivars while percentage parasitism of $C$. unimaculata distinctly increased on two of the four cultivars tested (figure 2). The trend in the third test was not as distinct as in the tests 1 and 2. This may have been due to a shorter sampling period and the stage of crop growth when sampling was conducted, which was during the period of 7-42 days after transplanting. The sampling period in tests 1 and 2 covered a later period of ca. 30-80 days after transplanting. In studies in Colombia, parasitism of the planthopper, Tagosodes orizicolus (Muir) by the strepsipteran Elenchus sp. increased with plant age while parasitism of T. cubanus did not (Arias et al., 1993).

Cofana unimaculata populations in this study were higher than those of $C$. spectra, which is in agreement with other surveys that we have conducted in West Africa (Heinrichs, unpublished). In view of the fact that $C$. spectra parasitism by Strepsiptera in this study (figure 4) and in studies on farmers' fields (Heinrichs, 1995) is higher than that of C. unimaculata parasitism, it is interesting to speculate as to whether the lower C. spectra population may be partially due to the higher rate of strepsipteran parasitism. However, the correlations between $C$. spectra populations and percent $C$. spectra parasitism on the various rice cultivars did not support this thesis.

Strepsipteran parasitism appears to be an important component in the suppression of Cofana spp. populations in West African rice fields. With the move to intensify rice production, and in accord with the attempt to develop sustainable rice production systems, it is important to determine the effects of alternative cultural practices on strepsipteran parasitism as a Cofana spp. population suppressing factor. In developing new technologies to meet the demand for rice in West Africa it is important to adopt technologies such as modern high-yielding rice cultivars, time of planting, fertilizer regimes, weeding practices, pesticide applications and other cultural practices that minimize pest populations and are compatible with maintaining high populations of Strepsiptera and other biocontrol agents. 


\section{References}

Arias, M., Cuevas, A. and Pantoja, A. 1993. Parasitization of Tagosodes orizicolus and T. cubanus in northeastern Colombian ricefields. International Rice Research Notes, 18(2), 32.

Barrion, A. T., and Litsinger, J. A. 1983. Parasites of white rice leafhopper Cofana spectra (Dist.) (Hemiptera: Cicadellidae) in the Philippines. International Rice Research Newsletter, 8(6), 20.

Barrion, A. T., and Litsinger, J. A. 1987. Strepsipteran parasites of rice leafhoppers and planthoppers in the Philippines. International Rice Research Newsletter, 12(4), 37-38.

Descamps, M. 1956. Insectes nuisibles du riz dans le nord Cameroun. Agronomie Tropicale, 11, 732-755.

Emosairue, S. O., and Usua, E. J. 1996. Upland rice insects in humid southeastern Nigeria. Global Journal of Pure and Applied Science, 2, 111-121.

Fox, J. W. 1967. Report on some Strepsiptera in the British Museum (Natural History), including new species of Halictophagidae and Elenchidae. Proceedings of the Royal Entomological Society of London (B), 36(3-4), 41-49.

Heinrichs, E. A. 1995. White leafhopper parasitism in Côte d'Ivoire. In WARDA Annual Report 1994 (Bouaké, Côte d'Ivoire: West Africa Rice Development Association).

Heinrichs, E. A., and Barrion, A. T. 2000. Biology and Ecology of Rice-Feeding Insects of West Africa (Los Baños, Philippines: International Rice Research Institute), to be published.

Hirashima, Y., and Kifune, T., 1978. Strepsipterous parasites of Homoptera injurious to the rice plant in Sarawak, Borneo, with description of a new species (Notulae Strepsipterologicae III). Esakia, No. 11, 53-58.

Kathirithamby, J. 1989. Review of the order Strepsiptera. Systematic Entomology, 14(1), 41-92.

Kathirithamby, J. 1992. Descriptions and biological notes of Halictophagidae (Strepsiptera) from Australia, with a checklist of the world genera and species. Invertebrate Taxonomy, 6, 159-196.

Olmi, M. 1998. A contribution to the knowledge of Dryinidae (Hymenoptera: Chrysidoidea) and Strepsiptera of Mozambique. Oriental Insects, 32(0), 59-78.

Pierce, D. W. 1909. A Monographic Revision of the Twisted Winged Insects Comprising the Order Strepsiptera Kirby. Smithsonian Institution, United States National Museum, Bulletin No. 66.

Reissig, W. H., Heinrichs, E. A., Litsinger, J. A., Moody, K., Fiedler, L., Mew, T. W., and Barrion, A. T. 1986. Illustrated Guide to Integrated Pest Management in Rice in Tropical Asia (Los Baños, Philippines: International Rice Research Institute).

Sam, M. D., and Chelliah, S., 1984. Biology of the white leafhopper on rice. International Rice Research Newsletter, 9(1), 22.

Sarawak Department of Agriculture. 1985. Annual Report of the Research Branch, Department of Agriculture for the Year 1983 (Sarawak, Malaysia: Ministry of Agriculture and Community Development).

Shepard, B. M., Barrion, A. T., and Litsinger, J. A. 1986. Friends of the Rice Farmer: Helpful Insects, Spiders, and Pathogens (Los Baños, Philippines: International Rice Research Institute).

Wilson, M. R., and Claridge, M. F. 1985. The leafhopper and planthopper fauna of rice fields. In L. R. Nault and J. G. Rodriguez (eds.), The Leafhoppers and Planthoppers (New York: John Wiley and Sons), pp. 381-404.

Wilson, M. R., and Claridge, M. F. 1991. Handbook for the Identification of Leafhoppers and Planthoppers of Rice (Wallingford, UK: CAB International). 